\title{
Determination of trace lead impurities in pure copper slurry samples by electrothermal atomic absorption spectrometry with molybdenum tube atomizer
}

\author{
S. Ahsan*, S. Kaneco, K. Ohta and T. Mizuno \\ Department of Chemistry for Materials, Faculty of Engineering, Mie University, Tsu, Mie 514-8507, Japan

\begin{abstract}
A method for direct atomization of slurry sample by electrothermal atomic absorption spectrometry (SS-ETAAS) has been developed for the determination of trace lead impurities in commercially available pure copper using laboratory-made molybdenum tube atomizer. Suitable charring temperature was set and matrix element interference was checked. Lead standard solution in the glycerol-water medium as calibration medium and ultrasonic agitation method of the suspension of the sample powder were used. Typical results of this direct slurry method and wet digestion were close and precision varies over the range RSD 3.9 to $9.0 \%$. The recovery of $\mathrm{Pb}$ added was $98-102 \%$. Accuracy for certified copper sample agreed within $3 \%$ range. Limits of detection were $34 \mathrm{fg} \mathrm{Pb}(3 \mathrm{~S} / \mathrm{N})$, and characteristic mass $170 \mathrm{fg} \mathrm{Pb}$. The method offers rapid calibration, simplified and fast analysis of lead in pure copper at lower cost.
\end{abstract}

Keywords. Lead - slurry sampling - copper sample - electrothermal atomization - molybdenum tube atomizer.

\section{Introduction}

In order to achieve a good quality of metal-based products in the industrial processes, it is essential to determine trace impurities in high purity metals. Generally most of the lead metal is harmful not only to biological life, but also is for the quality of some industrial products. Presence of low concentration of lead impurities can cause various mechanical and qualitative problems to copper-based and other metal products. The permissible content of lead in copper-based manufacturing products depends solely on the types of products to which it is to be used. For example, to a lesser extent, it markedly effects the annealibility of copper used in wire production and can exert harmful effects at low level below $1 \mu \mathrm{g} \cdot \mathrm{g}^{-1}$ [1]. Serious impairment of electrical conductivity develops when lead content of copper raw material used for electrical purpose exceeds $8 \mu \mathrm{g} \cdot \mathrm{g}^{-1}$, whereas in the copper based alloys used for wielding it is required to be below $20 \mu \mathrm{g} \cdot \mathrm{g}^{-1}$ in lead content to prevent cracking. On the contrary, in other industrial processes much higher levels of lead may be required in copper alloys [2].

Atomic spectrometric methods e.g., ETAAS and ICPOES [3-6] and electrochemical methods [7] have so far been applied in the determination of trace impurities of various high purity materials. The advent of ICP-MS attempted to determine traces of impurities in high purity metals both with and without preconcentration [3,8]. Direct applicability of this powerful analytical tool for the determination of trace impurities may also be restricted due to the matrix interference. However, in spite of many drawbacks, the interest in developing the solid sampling for trace metals analysis by ETAAS is evident from the large number of papers published [9]. According to a review literature [10], a versatile method complimentary to direct solid sampling for trace metal analysis is slurry sampling. It also notes that slurry sampling has broadened the potential of ETAAS techniques for increasing application in numerous analytical tasks. For the determination of traces of metals by electrothermal atomizers many researchers have performed direct atomization of various types of environmental [11-13] and metal oxide samples [14-15] using slurry suspension.

In recent years use of the ETAAS with metal tube atomizers is gradually growing more interest among researchers. These atomizers have so far shown superior performance and better sensitivity for most metal elements than graphite furnaces, flame furnaces and other analytical methods, primarily due to their ability to use smaller sample size, relatively low power consumption and low cost [16]. Several studies [17-20] have reported use of the molybdenum tube, tungsten coil and filament atomizers for the determination of lead in biological and environmental samples by ETAAS. Direct determination of trace impurities in high purity metals and its alloys using metal tube atomizers have not been reported so far. Beside that, there is growing need for a high sensitive rapid method to screen out the trace of impurities in industrial materials, which led to this research initiative to develop rapid analytical methodology as well as to optimize the already existing one. 
In this study, we reported the investigation and feasibility on the determination of lead by application of slurried pure copper sample using ETAAS with molybdenum tube atomizer.

\section{Materials and methods}

\section{Instrumentation}

$\mathrm{Pb}$ determinations were performed with a Nippon JarrellAsh 0.5-m Ebert-type monochromator atomic absorption spectrometer equipped with R943 photomultiplier tube (Hamamatsu Photonics Co.), a fast response amplifier, a storage oscilloscope (Iwatsu MS-5021) and a microcomputer (PC 9801FA, NEC Corporation, Japan). An atomizer consisting of molybdenum tube $(20 \mathrm{~mm}$ long and $1.8 \mathrm{~mm}$ i.d.) and two supporters (5 mm wide and $20 \mathrm{~mm}$ long) made from high purity molybdenum sheet (99.5\% purity, $0.05 \mathrm{~mm}$ thick, Rembar Co.) was used for direct atomization of sample. Laboratory made $1 \mu \mathrm{l}$ glass micropipette was used to inject the slurry sample through a $0.3-\mathrm{mm}$ diameter hole at the mid point of the molybdenum tube atomizer. Instrumental condition set for all determination included resonance line of $217.0 \mathrm{~nm}$ (Pb-hollow cathode lamp, Hamamatsu Photonics Co.), a deuterium lamp (Original Hanau D200F) to compensate background absorption, a step down transformer and a transformer (Yamabishi volt-slider, S-130-30, capacity $3 \mathrm{KVA}$ ) to supply electric power for heating the atomizer, two pinholes apertures placed in front and at the rear end of the atomizer to collimate the light beam and eliminate radiation from atomizer surface. The absorption signal from the amplifier and the output signal from a photodiod for the measurement of atomizer temperature were simultaneously fed into microprocessor, calibration of the temperature of the atomizer was done against the photodiode voltage using an optical pyrometer (Chino Works) with a microcomputer programming. Baseline was measured by heating without sample. The time constant was $4 \mathrm{~ms}$. The atomic absorption signal was evaluated from the peak height.

The sample mass of chemicals were determined by using a semimicro analytical balance $\mathrm{H} 20$ (Mettler) providing a precision of $\pm 0.01 \mathrm{mg}$. Commercially available average $100 \mu \mathrm{m}$ pure copper sample powder was grounded to obtain various particle diameters using an agate mortar and a filter (Nippon Rikagaku Kikai, ISO 38). An optical microscope (Kenko, KL-1200) was used to determine the particle diameter of grounded powder copper sample. An Uni-seal decomposition vessel was used for digestion of sample. Ultrasonic washing apparatus (UT-4, 26 KHZ, Kokusai Electric Co.) used to homogenize slurried copper samples immediately before sample injection. Ultrapure water was prepared using Adventec ultrapure water system CW-102.

\section{Samples and reagents}

Commercially available pure copper powder (average $100 \mu \mathrm{m}$ size) sample was made available from (The Nilaco
Corporation, Japan) and reference copper sample were provided by (The Good Fellow, England).

A standard lead solution (10 and $20 \mathrm{ng} \cdot \mathrm{ml}^{-1}, 0.001 \mathrm{M}$ nitric acid) was prepared from $\mathrm{Pb}\left(\mathrm{NO}_{3}\right)_{2}$ in $0.1 \mathrm{M}$ nitric acid, obtained from (Wako Pure Chemical Industries Ltd, Japan). Pure glycerol used as solvent obtained from (Nacalai Tesque, Japan). Working standard solutions with appropriate concentrations were prepared by dilution of stock standard solutions with pure water immediately before use. $\mathrm{H}_{2} \mathrm{O}_{2}$ (30 \%) and $0.05 \mathrm{M}$ nitric acid used for acid digestion obtained from (Santoku Chemical Industries, Japan and Nacalai Tesque, Japan, respectively). All reagents and chemicals used were of analytical grade or spectroscopic purity.

\section{Procedures for slurry sampling}

Pure copper sample $(100 \mu \mathrm{m})$ was used to make different average particle diameter of $26 \mu \mathrm{m}, 38 \mu \mathrm{m}$ and $75 \mu \mathrm{m}$ by grounding and filtration. An accurately weighed $0.03 \mathrm{~g}$ copper (38 $\mu \mathrm{m}$ size) sample with $3 \mathrm{ml}$ hydrogen peroxide $(30 \%)$ and $1 \mathrm{ml}(0.05 \mathrm{M})$ nitric acid was digested in a Uniseal decomposition vessel and heated at $120{ }^{\circ} \mathrm{C}$ for $3 \mathrm{~h}$ in an electric oven. After cooling the acid-digested sample was dissolved to desired volume with a $15: 85 \mathrm{ml}$ ratio of glycerol:pure water. Alternatively, $0.03 \mathrm{~g}$ of powdered copper samples $(38 \mu \mathrm{m}$ size) were transferred into a $100 \mathrm{ml}$ volumetric flask and completed to desired volume by glycerol and pure water in the afore mentioned proportion. Immediately before sample injection an ultrasonic agitation ( $5 \mathrm{~min}$ ) was performed to homogenize the suspension. For the determination of lead in slurried pure copper samples, a calibration curve was constructed using standard solution containing 10 and $20 \mathrm{ng} \cdot \mathrm{ml}^{-1}$ of $\mathrm{Pb}$ dissolved in glycerol:water medium, $1 \mu \mathrm{l}$ aliquot of which was pipetted into the molybdenum tube atomizer.

\section{Results and discussion}

According to Suzuki et al. [21], metal tube atomizer provides with an uniform temperature of the atomizer body and a more dense atom cloud at a short period of time than graphite atomizers. Under this condition absorption profile of lead could be characterized by narrower peak with increasing heating rate, thereby, deviation of the individual values from the calibration curves are smaller using the peak-height mode than with integrated value; this suggests preferential use of peak-height mode for the direct analysis. In this study, the suitable atomization temperature employed for lead measurements was $2160{ }^{\circ} \mathrm{C}$ (heating rate $3.6{ }^{\circ} \mathrm{C} / \mathrm{ms}$ ). To increase the sensitivity for some metals and also to protect the atomizer from oxidation by traces of oxygen in the argon, few authors [22-23] suggested to add hydrogen into purge gas. In this experiment we have employed the flow rates $\mathrm{Ar} 480 \mathrm{ml} \cdot \mathrm{min}^{-1}$ added to $\mathrm{H}_{2}$ $20 \mathrm{ml} \cdot \mathrm{min}^{-1}$ as studied by Suzuki et al. [24], the optimal purge gas flow rate for lead atomization in a molybdenum tube atomizer. 


\section{Original articles}

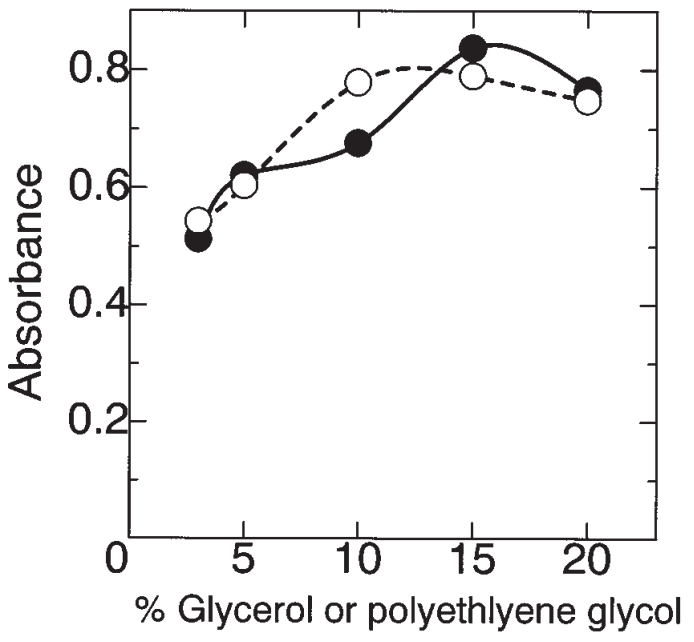

Figure 1. Effect of liquid medium on the absorption signal of lead. $\bigcirc$ Polyethylene Glycol; Glycerol.

\section{Slurrying medium}

In this study we tried to evaluate a suitable liquid medium which produces a satisfactory dispersion and homogeneity of the slurried $\mathrm{Cu}$ sample. As a matter of choice typical solvents, polyethylene glycol (PEG) and glycerol with a mixing ratio $(3,5,10,15$ and $20 \%)$ were used as the medium for dispersion of solid particles. Analyte signals of both PEG and glycerol are shown in figure 1. Although glycerol gives the highest sensitivity at $15 \%$ mixing ratio, the analyte signal is less affected by variation in the PEG composition, which implies that homogeneity of $\mathrm{Pb}$ slurried in both the solvent is good. In the study of Hoenig and Van Hoeyweghen [25] test results have shown that the viscosity of glycerol kept the different types of particles in suspension for a sufficient time. Moreover, during charring step, in spite of heavy smoke due to decomposition of glycerol, no significant background signals were generated in the atomization step. Therefore, 15:85 mixing ratio of glycerol was selected as slurrying medium for this experiment as most sensitive analyte signal was observed.

\section{Optimization of charring temperature}

In the ETAAS method, the optimization of charring temperature for different kind of samples is essential, as it has been reported [21] to have effects on the AA-peak heights in the determination of some elements. Charring temperature for elemental analysis in a specific matrix may vary considerably with the type of sample, atomizer and other factors [26]. In one of earlier study [17] we have applied a charring temperature of $370{ }^{\circ} \mathrm{C}$ for the determination of lead in drug sample using metal tube atomizer. Nevertheless, to obtain the best optimization of charring temperature for the

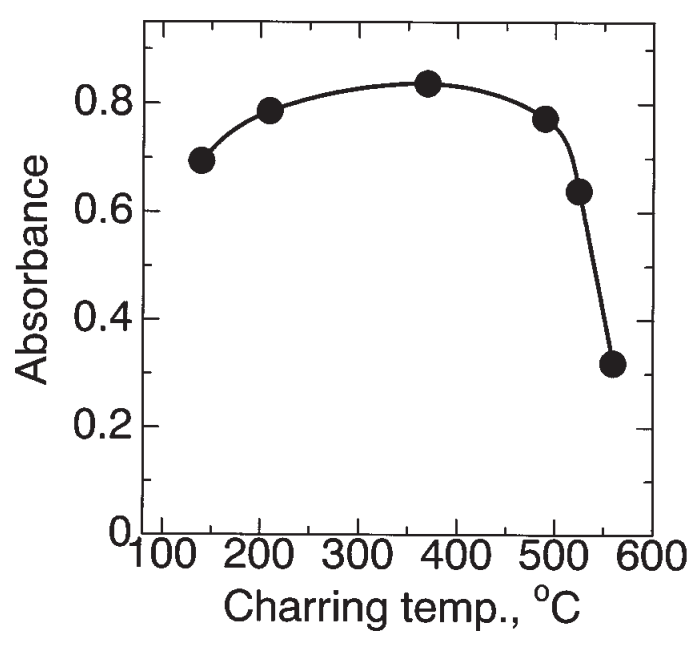

Figure 2. Effect of charring temperature on the peak height of $\mathrm{Pb}$ in pure Copper. Purge gas: Ar $480 \mathrm{ml} \cdot \mathrm{min}^{-1}$ and $\mathrm{H}_{2} 20 \mathrm{ml} \cdot \mathrm{min}^{-1}$; drying temperature $100{ }^{\circ} \mathrm{C}$, atomization temperature $2160{ }^{\circ} \mathrm{C}$.

copper sample slurried in glycerol-water medium, we investigated the influence of charring temperature using molybdenum tube atomizer. Figure 2 represents the effect of charring temperature in the range of $\left(140{ }^{\circ} \mathrm{C}-560{ }^{\circ} \mathrm{C}\right)$ on the peak height absorption signal of lead. With increasing temperature the signal has shown an increasing trend, however it remained more or less stable in the range between $200 \mu \mathrm{C}$ to $490{ }^{\circ} \mathrm{C}$. With the Mo-tube, the appearance temperature, which is defined as the temperature of the atomizer giving a absorbance of 0.0044 of lead in the presence of copper matrix was $1020{ }^{\circ} \mathrm{C}$. For the determination of lead by GFAAS using $\mathrm{NH}_{4} \mathrm{H}_{2} \mathrm{PO}_{4}$ and palladium as modifiers, a charring temperature of $700-900{ }^{\circ} \mathrm{C}$ [27], and $1000{ }^{\circ} \mathrm{C}$ [28] was reported. But in this instance, the absorption signal abruptly decreased at $560{ }^{\circ} \mathrm{C}$. The suitable charring temperature was observed in the range of $370{ }^{\circ} \mathrm{C}-490{ }^{\circ} \mathrm{C}$.

\section{Study on matrix interferences}

Unlike many other trace elements, determination of lead is sensitive to matrix interferences. Ohta et al.[19] studied the interference effect of $\mathrm{Cu}$ matrix on the lead determination with a $200{ }^{\circ} \mathrm{C}$ charring temperature and concluded that it is negligible. In order to ascertain the matrix effect of $\mathrm{Cu}$ on the lead determination, an experiment was conducted with 10,000-fold of $\mathrm{Cu}$. The choice of two different charring temperatures for interference study were made based on the best analyte signal obtained during optimization of charring temperature. At $490{ }^{\circ} \mathrm{C}$ the $\mathrm{Pb}$ aqueous solution and matrix mixture produced a sharper absorption peak signals, on the other hand a marginal shift in peak signals occurred at $370{ }^{\circ} \mathrm{C}$. The relative standard deviation (RSD) calculated at $490{ }^{\circ} \mathrm{C}$ was lower than the RSD determined at $370{ }^{\circ} \mathrm{C}$. Therefore, $490{ }^{\circ} \mathrm{C}$ was selected as charring temperature for 


\section{Original articles}

this experiment since atomization profile was reproducible and the use of chemical modifier was not necessary.

\section{Particle diameter}

Solid substances are usually polycrystals and trace elements are distributed in a wide variety of spatial conditions; some are dispersed homogeneously within whole crystals, whereas others are concentrated in grain boundaries. Therefore, many authors [29-32] reported that when solid or slurry samples are analyzed by ETAAS, the establishment of optimal condition concerning particle diameter is essential to achieve the best reproducibility. In the studies of Nakamura et al. smaller particle diameter of tooth sample [33] silicate rocks [34], and quartz [35] demonstrated the best reproducibility. Usually accuracy and precision of measurement in slurry can be affected either by inadequate homogeneity or poor sample representivity, and/or incomplete recovery of analyte from the matrix during atomization process. Therefore, an investigation was performed to assess the effect of different particle diameters: $100 \mu \mathrm{m}, 75 \mu \mathrm{m}, 38 \mu \mathrm{m}$ and $26 \mu \mathrm{m}$ of pure copper, respectively. Noticeable changes in absorption were observed with variation in particle diameter. Absorption gradually increased with smaller particle diameter together with decrease in relative standard deviation (Tab. I). These phenomena are due to better homogeneity of relatively small size of suspended particles. However, with 38 and $26 \mu \mathrm{m}$ the absorption signals were almost similar, likely indicates that the best saturation of the analyte element occurred at these particle diameter. RSDS with larger size are certainly due to variation of the number of particles sampled. Hence, an average particle diameter of $38 \mu \mathrm{m}$ has been chosen for the determination of lead impurities in copper samples.

\section{Use of ultrasonic agitation}

Among few practiced techniques for sample stabilization and homogenization, ultrasonication is found to be one of the most efficient method. In earlier studies $[17,36]$ we have applied the ultrasonic agitation for the slurried drug samples: it performed a good dispersion of these samples. In this work we also investigated the effect of ultrasonication: the results are shown in figure 3. Absorption peak was lowest

Table I. Effect of particle size of high purity copper on lead absorbance and r.s.d of the absorbance.

\begin{tabular}{lcl}
\hline $\begin{array}{l}\text { Average particle } \\
\text { size, } \mu m\end{array}$ & absorbance & $\%$ RSD \\
\hline $100 \pm 1$ & 0.232 & $3.0 \%$ \\
$75 \pm 1$ & 0.268 & $2.3 \%$ \\
$38 \pm 1$ & 0.387 & $2.0 \%$ \\
$26 \pm 1$ & 0.392 & $2.0 \%$ \\
\hline
\end{tabular}

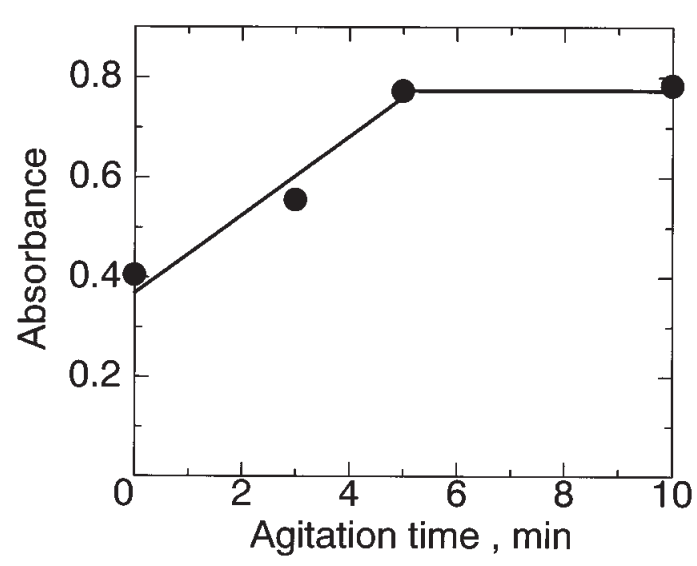

Figure 3. Effect of ultrasonic agitation time.

at zero agitation with manual stirring about 2-3 s. While after ultrasonication the absorption peak increased until $5 \mathrm{~min}$ agitation time and became plateau at more than $5 \mathrm{~min}$ and also the relative standard deviation calculated from 5 repeated measurements was good since 5 min agitation. Therefore, from this result the agitation time of 5 min was selected for copper samples.

\section{Characteristic mass, detection limit and reproducibility}

Computed from the lower linear portion of the calibration curve and deviation of baseline on blank firings, the absolute characteristic mass (gave an peak absorbance of 0.0044 ) of lead was $170 \mathrm{fg}$ and the limit of detection was $34 \mathrm{fg}(3 \mathrm{~S} / \mathrm{N}$, corresponding to $3.4 \mathrm{pg} \cdot \mathrm{ml}^{-1}, 10 \mu \mathrm{l}$ injected). From this value $1.1 \mathrm{pg} \cdot \mathrm{g}^{-1}$ is estimated as detection limit of lead in copper metal. The value is better than the limits of detection obtained by introduction of slurry sample of foodstuffs without modifier (5 $\left.\mathrm{ng} \cdot \mathrm{g}^{-1}\right)$ [37], and also for cereal based products with phosphate as modifier $\left(8 \mathrm{ng} \cdot \mathrm{g}^{-1}\right)$ [38] both using GF-ETAAS method. A reason for better sensitivity observed with molybdenum tube atomizer is presumably due to nonporosity of the wall of the atomizer [39], and also certainly due to narrower diameter of the tube compared to graphite furnaces.

A relative standard deviation of $3 \%$ was obtained for lead (10 $\mathrm{ng} \cdot \mathrm{ml}^{-1}, 1 \mu \mathrm{l}$, corresponding to $10 \mathrm{pg}$ of lead) for 10 measurements.

\section{Analysis of lead in copper samples}

The proposed method of slurry sampling by ETAAS with molybdenum tube atomizer has been applied to the analysis of trace amount of lead in pure copper samples together with an evaluation of the analytical method by application to standard reference samples. Optimum analytical conditions 
Table II. Experimental Condition for slurry analysis of $\mathrm{Pb}$ in high purity copper.

\begin{tabular}{lc}
\hline Element & $\mathrm{Pb}$ \\
\hline Wavelength & $217.0 \mathrm{~nm}$ \\
& \\
Argon flow & $480 \mathrm{ml} \cdot \mathrm{min}^{-1}$ \\
Hydrogen flow & $20 \mathrm{ml} \cdot \mathrm{min}^{-1}$ \\
Drying step & $100^{\circ} \mathrm{C}(30 \mathrm{~s})$ \\
Charring step & $490{ }^{\circ} \mathrm{C}(40 \mathrm{~s})$ \\
Atomization step & $2160{ }^{\circ} \mathrm{C}(3 \mathrm{~s})$ \\
Calibration range & $0-20 \mathrm{ng} \cdot \mathrm{ml}^{-1}$ \\
\hline
\end{tabular}

applied for this method is presented in table II. The average particle diameter of the samples was $38 \mu \mathrm{m}$. For accurate determination of lead in the slurried sample and acid digested copper, samples were diluted in a pure glycerolwater mixture medium to an appropriate volume. A linear calibration graph was drawn from 10 and $20 \mathrm{ng} \cdot \mathrm{ml}^{-1}$ of $\mathrm{Pb}$ solutions. Negligible background absorption signals were observed for copper samples by using a deuterium lamp light source. The content of lead determined in pure copper samples is presented in table III. Results of the direct slurry atomization method are in good agreement with the acid digestion method. In both instances the relative standard deviation for five replicate analysis were in the range of $3.9 \%$ to $9.0 \%$, which is reasonably good for direct slurry sampling technique. The recovery of lead concentration spiked in the copper sample are in the range of 98\%-102\%. This suggest that the analytical method is precise and reliable. Analytical test results of direct slurry sampling and acid digested methods were compared by performing a statistical interpretation of student's $t$-test. Confidence limit were within $95 \%$ range, which shows very insignificant difference.

\section{Conclusion}

The technique for the direct analysis of slurry samples employing a laboratory constructed molybdenum tube atom- izer was found to be an appropriate approach in the analysis of lead in pure copper samples. Use of molybdenum tube atomizer together with argon-hydrogen atmosphere offers benefit of higher sensitivity and longer lifetime of metal tube (more than 5000 firings) compared to 200-250 firings for graphite furnaces [40] and the performance characteristic of molybdenum tube atomizer also serve to provide sensitive determination of metal. Therefore, a conventional method is proposed to ensure a reliable measurement of $\mathrm{Pb}$ in high purity metals with good accuracy.

\section{Acknowledgements}

This research was supported by the Ministry of Education and Culture of Japan.

\section{References}

1. Hallam, D.C. Wire J. 1977, 10, 115.

2. Shaw, F.; Ottaway, J.M. At. Absorp. Newslett. 1974, 3, 77.

3. Kudermann, G. Fresenius' J. Anal. Chem. 1988, 331, 697.

4. Tanaka, T.; Maki, Y.; Kobayashi, Y.; Mizuike, A. Anal. Chim. Acta 1991, 252, 211.

5. Hinds, M.W. J. Anal. At. Spectrom. 1992, 7, 685.

6. Yudelevich, I.G.; Zakda, B.I.; Shabarova, V.P.; Chereko, A. S. At. Spectrosc. 1992, 13, 108.

7. Naumann, R.; Schmidt, W.; Höh, G. Fresenius'J. Anal. Chem. 1990, 347, 133 .

8. Stummeye, R.J.; Wünsch, G. Fresenius' J. Anal. Chem. 1991, 340, 269.

9. Bendicho, C.; de Loos-Vollebergt, M.T.C. J. Anal. At. Spectrom. 1991, 6, 353.

10. Kurfürst, U (Ed.) Solid Sample Analysis; Berlin: SpringerVerlag, 1998, p 247.

11. Yu, Z.; Vandecasteele, C.; Desment, B.; Dams, R. Mikrochim. Acta [Wien]I 1990, 41.

12. Hinds. M.W.; Latimer. K.E.; Jackson. K.W. J. Anal. At. Spectrom. 1991, 6, 473.

13. Bermejo-Berrera, P.; Barcelia-Alonso, M. C.; Moreda-Pinerio, J.; Gonzàlez-Sixto, C.; Bermejo-Berrera, A. Spectrochim. Acta. 1996, $51 B, 1235$

14. Docecal, B.; Krivan, V. J. Anal. At. Spectrom. 1993, 8, 637.

Table III. Determination of lead in high purity copper samples.

\begin{tabular}{|c|c|c|c|c|c|}
\hline \multirow[b]{2}{*}{ Sample } & \multicolumn{5}{|c|}{ [Concentration of lead, $\mu g \cdot g^{-1}$ ] } \\
\hline & Spiked & Slurry analysis & Recovery & Acid digestion & Certified value \\
\hline CU-114125 & - & $69.2 \pm 4.0(6.0 \%)$ & - & $70.0 \pm 2.0$ & \\
\hline (NILACO Corp.) & 8.3 & $77.4 \pm 3.0(3.9 \%)$ & $98 \%$ & & \\
\hline & 16.7 & $86.2 \pm 7.8(9.0 \%)$ & $102 \%$ & & \\
\hline $\begin{array}{l}\text { CU-6045 } \\
\text { (GOOD FELLOW) }\end{array}$ & - & $103.0 \pm 7.0(6.8 \%)$ & - & & 100 \\
\hline
\end{tabular}

$n=>5$

$\mathrm{RSD}$ in parenthesis 


\section{Original articles}

15. Hauptkorn, S.; Schneider, G.; Krivan, V. J. Anal. At. Spectrom. 1994, 9, 463.

16. Ohta, K.; Kaneco, S.; Itoh, S.; Mizuno, T. Anal. Chim. Acta 1992, 267, 131-136.

17. Ahsan, S.; Kaneko, S.; Ohta, K.; Mizuno, T.; Suzuki, T.; Miyada, M.; Tanuguchi, Y. Anal. Chim. Acta 1998, 362, 279.

18. Krug, F.J.; Silva, M.M.; Oliveira, P.V.; Nobrega, J.A. Spectrochim. Acta 1995, Part B 50, 1469.

19. Parsons, P.J.; Qiao, H.; Aldous, K,M.; Mills, E.; Slavin, W. Spectrochim. Acta 1995, Part B, 50, 1475.

20. Bruhn, C.G.; Ambido, F.E.; Cid, H.J.; Woerner, R.; Tapia, J.; Garcia, R. Anal. Chim. Acta 1995, 306, 183.

21. Suzuki, M.; Ohta, K. Prog. Anal. At. Spectrosc. 1983, 6, 49.

22. Frech, W.; Cedergren, A. Anal. Chim. Acta 1976, 82, 83.

23. Routh, M. W. Anal. Chem. 1980, 52, 182.

24. Suzuki, M.; Ohta, K. Anal. Chem. 1982, 54, 1686.

25. Hoenig, M.; Hoeyweghen, P.V. Anal. Chem. 1986, 58, 2814.

26 Langmhyr, F. J.; Wibetoe, G. Prog. Anal. At. Spectrosc. 1985, $8,207-218$

27. May, T.W.; Brumbaugh, W.G. Anal. Chim. Acta 1982, 54, 1034.

28. Bermejo-Berrera, P.; Moreda-Pinerio, A.; Moreda-Pinerio, J.; Bermejo-Berrera, A. Anal. Chim. Acta 1995, 310, 355.
29. Mirezawa, J.; Dobrowolski, R. Fresenius' Z. Anal. Chem. 1994, 348, 422.

30. Schneider, G.; Krivan, V. Spectrochim. Acta. 1995, B 50, 1557.

31. Stephen, S.C.; Ottaway, J.M.; Littlejohn, D. Fresenius' Z. Anal. Chem. 1987, 328, 346.

32. Miller-Ihli, N.J. Fresenius' Z. Anal Chem. 1990, 337, 271.

33. Nakamura, T.; Kusata, T.; Matsumoto, H.; Sato, J. J. Anal. Biochem. 1995, 226, 256.

34. Nakamura, T.; Oka, H.; Morikawa, H.; Sato, J. Analyst 1992, 117,131

35. Nakamura, T.; Sasagawa, R.; Sato, J. Bunseki Kagaku. 1992, 41,89 .

36. Ahsan, S.; Kaneco, S.; Ohta, K.; Mizuno, T.; Tanuguchi, Y. Talanta 1999, 48, 63.

37. Littlejohn, D.; Stephen, S.C.; Ottaway, M. Anal. Proc. 1985, $22,376$.

38. Viñas, P.; Campillo, N,; Lòpez-Garcìa, I.; Hernàndez-Còrdoba, M. Fresenius J. Anal. Chem. 1994, 349, 306.

39. Zheng, Y.; Woodriff, R.; Nicholas, J.A. Anal. Chem. 1984, 56, 1388.

40. Bettinelli, M.; Baroni, U.; Fontana, F.; Poisetti, P. Analyst 1985, 19, 110 . 